\title{
Successful single-stage transperitoneal laparoscopic ureterolithotomy in a solitary functioning renal unit with multiple large ureteric calculi along its entire length
}

\author{
Sheshang U. Kamath*, Deepak Kaddu, Bhushan Patil and Sujata K. Patwardhan
}

\begin{abstract}
Background: Laparoscopic ureterolithotomy bridges the gap between open and endourologic procedures as it is minimally invasive and overcomes a few of the disadvantages of open ureterolithotomy. We report a case of a solitary functioning renal unit with at least 12 large ureteric calculi coursing along the entire length of the ureter and involving the renal pelvis presenting with obstructive uropathy which was subsequently successfully managed with laparoscopic ureterolithotomy.

Case presentation: A 50-year-old male patient presented with obstructive uropathy with CT suggestive of solitary functioning right kidney with right ureter showing at least 13 large ureteric calculi and large renal pelvic calculi. Right transperitoneal laparoscopic ureterolithotomy was performed. All the renal and ureteric calculi were successfully removed.

Conclusion: Thus, laparoscopic ureterolithotomy with only three ports can be used to remove any burden of calculi along the course of the entire urinary tract being successful in a single stage with minimal morbidity.
\end{abstract}

Keywords: Laparoscopic, Ureterolithotomy, Ureter

\section{Background}

In the present endoscopic era, the indications for open surgery for stone disease range from 1.0 to $5.4 \%$ [1-4]. The use of laser has further increased the interest of urologist in ureteroscopic stone fragmentation of even multiple large ureteric calculi [5]. Although ureterolithotomy has its own set of drawbacks, it still holds ground in stones which are inaccessible and difficult to fragment by endourologic procedures [6]. Laparoscopic ureterolithotomy bridges the gap between open and endourologic procedures as it is minimally invasive and overcomes a few of the disadvantages of open ureterolithotomy. There have been few case reports of

\footnotetext{
*Correspondence: sheshangkamath@gmail.com

Department of Urology, Seth G.S. Medical College and K.E.M Hospital, Mumbai, India
}

laparoscopic ureterolithotomy being successfully used for giant calculus and multiple calculus involving lower and mid-ureter; however, none to our knowledge have tackled multiple ureteric calculus coursing along the length of the ureteric and the renal pelvis. We report a case of a solitary functioning renal unit with at least 12 large ureteric calculi coursing along the entire length of the ureter and involving the renal pelvis presenting with obstructive uropathy which was subsequently successfully managed with laparoscopic ureterolithotomy.

\section{Case presentation}

A 50-year-old male patient presented with fever, oliguria, vomiting and bilateral flank pain since 3 days. On clinical examination, patient was conscious with a pulse rate of 100 and blood pressure of 130/90 mmHg. The patient had bilateral pitting pedal oedema and abdominal 
distension. On investigating him further, he had haemoglobin of $10.6 \mathrm{gm} / \mathrm{dL}$ with complete blood counts of $18,900 / \mathrm{cmm}$ and platelets of $1.5 \mathrm{lacs} / \mathrm{cmm}$. Renal function tests revealed BUN of $24 \mathrm{mg} / \mathrm{dL}$ and creatinine of $9.4 \mathrm{mg} / \mathrm{dL}$, and electrolytes and liver function tests were within normal limits. CT KUB with 3D reconstruction was done which showed left gross hydronephrosis with paper-thin parenchyma and a $26 \times 19 \mathrm{~mm}$ sized calculus at the left PUJ. Right kidney showed moderate hydronephrosis with multiple (at least 13 calculi identified) calculi in the entire right ureter, the largest calculus measures $19 \times 16 \mathrm{~mm}$ in size. A $5.0 \times 2.5 \mathrm{cms}$ sized calculus is noted in the right renal pelvis extending into the lower calyx. Few (5) $8-10-\mathrm{mm}$ calculi are noted in the right renal calyces (Fig. 1). The patient was diagnosed to have acute kidney injury, and bilateral percutaneous nephrostomy (PCN) was inserted which drained turbid urine. Urine from PCN grew Klebsiella sp. sensitive to meropenem, and antibiotic was started accordingly. On reassessment after 5 days, the patient had a creatinine of $3.5 \mathrm{mg} / \mathrm{dL}$ and daily urine output from left PCN was $100 \mathrm{~mL}$ and from right was $1300 \mathrm{~mL}$. EC scan revealed nonfunctioning left kidney with right kidney having an ERPF of $60 \mathrm{~mL} / \mathrm{min}$. After the urine culture was sterile, patient was posted for right transperitoneal laparoscopic ureterolithotomy.

The patient was given right flank-up position, and ports were inserted after creating pneumoperitoneum with a Veress needle (Fig. 2). Ascending colon and peritoneum reflected medially and kidney identified. Ureter was traced from below upward till renal pelvis, and stones were palpated along the course of ureter.

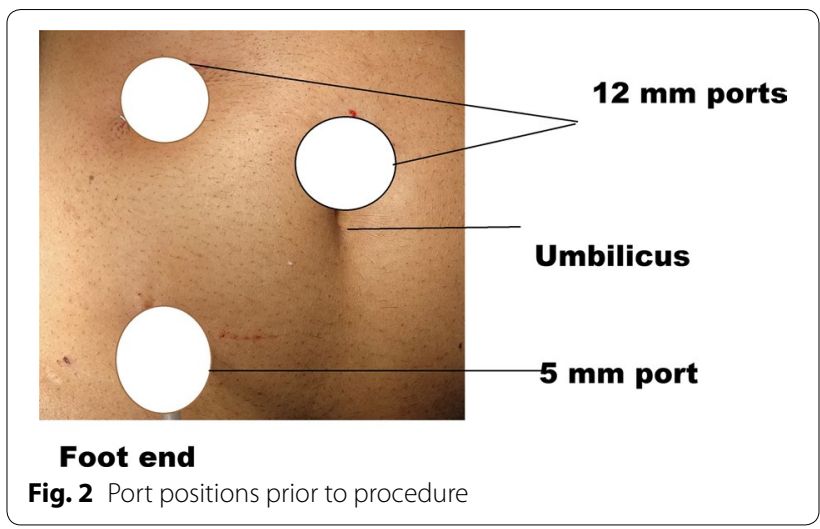

Incision was taken over the stone in lower ureter medially and ureter opened; nine stones were retrieved from mid- and lower ureter (Fig. 3). Upper ureteric incision of $2 \mathrm{cms}$ was taken extending into the pelviureteric junction, and two upper ureteric stones were removed and one pelvic removed. 6/26 Fr. DJ stent was kept over guide wire (Fig. 4). Ureteric incisions were closed with 3.0 Vicryl continuous sutures over 6/26 Fr. DJ stent. All stones were secured in a retrieval bag (Fig. 5) and removed outside through port-site incision. Abdominal drain of $16 \mathrm{Fr}$ was kept. Blood loss was $100 \mathrm{~mL}$, and operative time was one and a half hour. All the stones retrieved are placed sequentially as were present in the ureter, which is demonstrated in Fig. 6. Post-operative image of abdomen is shown in Fig. 7.
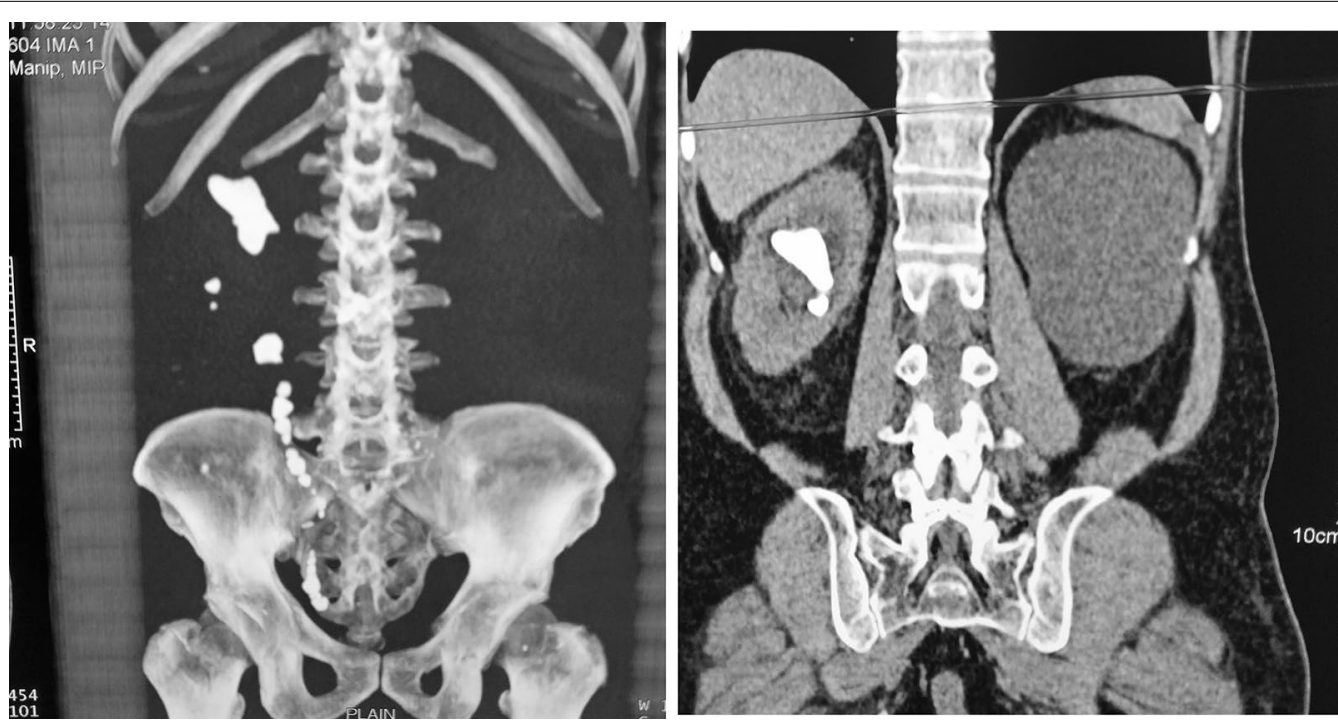

Fig. 1 CT KUB image of the patient posted for procedure 


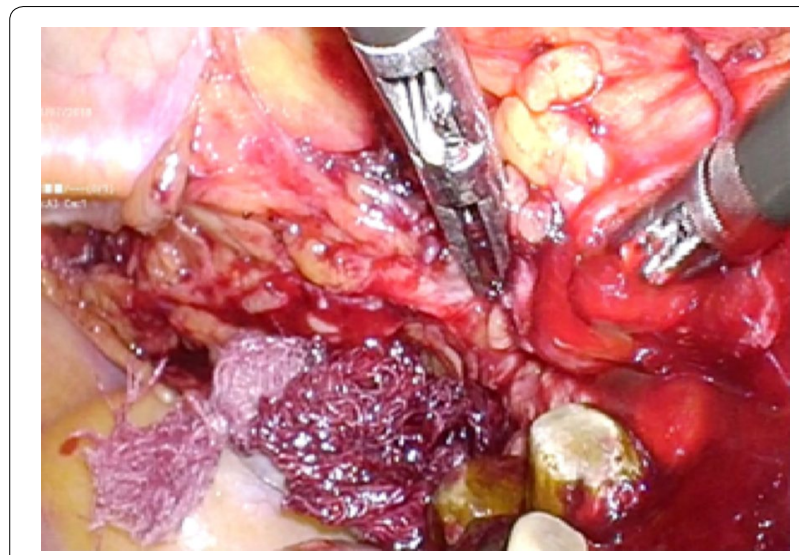

Fig. 3 Incision on ureter with the removal of stones

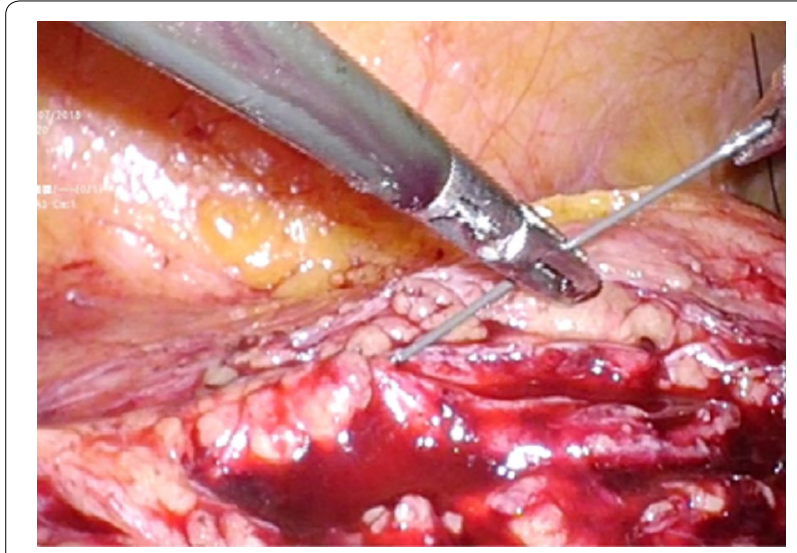

Fig. 4 DJ stent insertion after ensuring complete clearance

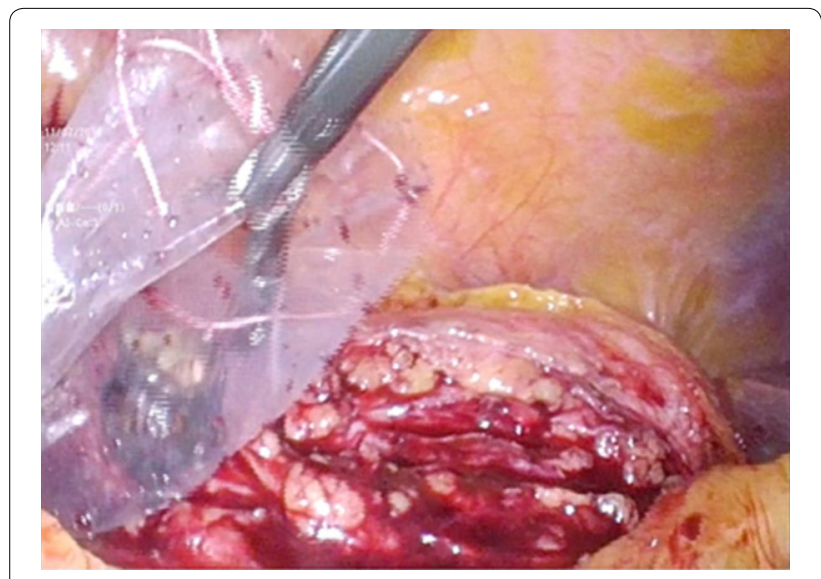

Fig. 5 Retrieval of stones in the endobag

Post-operative course was uneventful with a nadir creatinine of $3.2 \mathrm{mg} / \mathrm{dL}$ and daily output of $1.5 \mathrm{~L}$. Drain was removed on post-operative day 3 , per urethral catheter
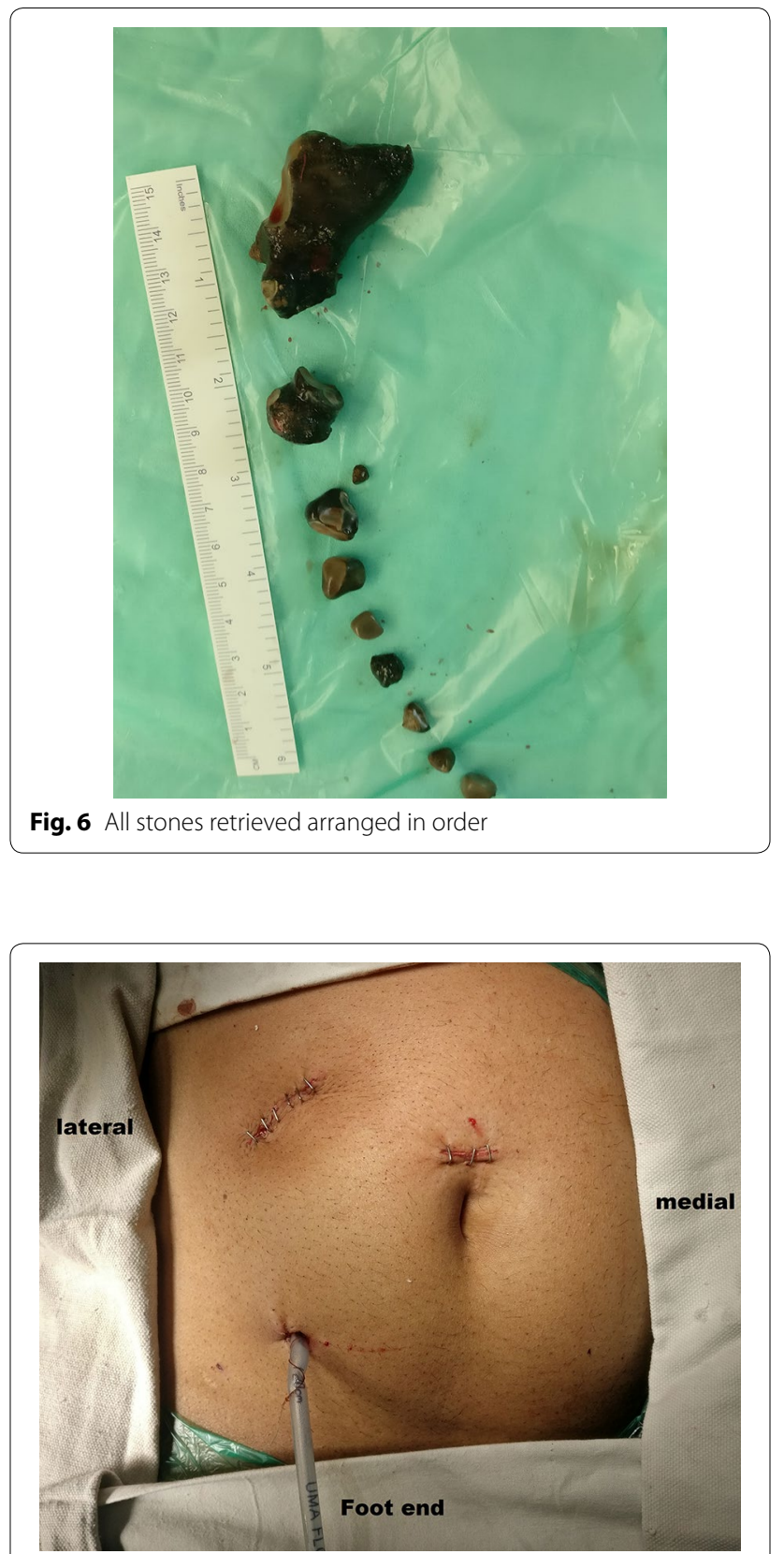

Fig. 7 Post-operative image of the patient

on day 4 and right $\mathrm{PCN}$ on day 7. Post-operative X-ray and USG revealed residual nonobstructive $8-\mathrm{mm}$ calculi in right lower pole (Fig. 8). DJ stent was removed on post-operative day 21.

\section{Discussion}

Impacted renal pelvic calculi as well as multiple ureteric calculi coursing along the entire length of the ureter in a solitary functioning kidney with acute obstructive uropathy pose unique challenges. Despite advances in 


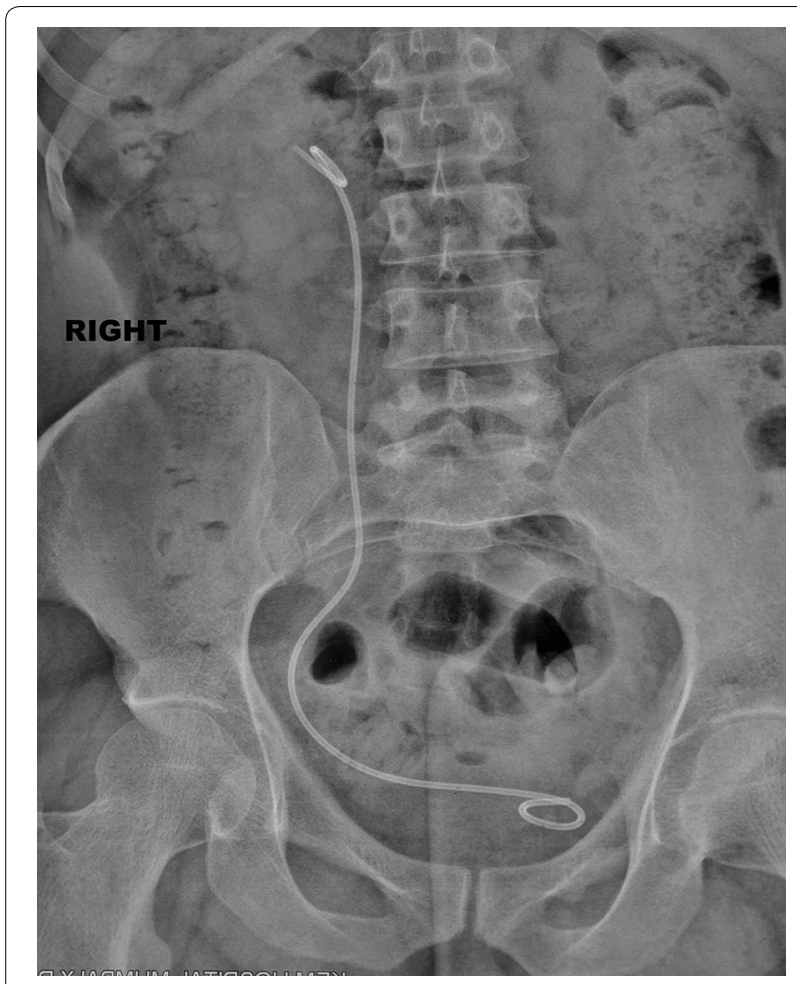

Fig. 8 Post-operative X-ray KUB was avoided as it decreases the vascularity and may result in injury by lateral currents [11]. Mid-ureteric calculi were removed from the same lower ureteric incision. Each stone was carefully retrieved and bagged, thereby avoiding losing any stone in the peritoneal cavity which is a major disadvantage of transperitoneal over retroperitoneal laparoscopic ureterolithotomy. Upper ureteric incision was used to retrieve the upper ureteric and renal pelvis calculi, and double J stent was placed laparoscopically which saved operative time. The incisions were meticulously sutured. Double J stent was used as mentioned in the previous literature to prevent complications like urinoma post-operatively in multiple large impacted calculi [12]. All the bagged stones were retrieved through an incision over the 12-mm port site to avoid slippage of any stone.

Laparoscopic procedures have their own set of disadvantages of injury to the viscera and loss of stone in peritoneal cavity as compared to endourologic procedures [13]. However, following principles of laparoscopy meticulously as mentioned above, the advantages outweigh these disadvantages in patients with such a large burden of stones and history of acute kidney injury. Also, perioperative antibiotics and urinary diversion helped prevent post-operative complications.

\section{Conclusion}

Thus, laparoscopic ureterolithotomy with only three ports can be used to remove any burden of calculi along the course of the entire urinary tract being successful in a single stage with minimal morbidity as laparoscopy helps visualize the entire ureter and renal pelvis after appropriate port insertion and meticulous dissection.

\section{Acknowledgements}

Not applicable.

\section{Authors' contributions}

SUK gave idea and collected the patients' data and analysed them. BP and DK were involved in study design and followed the patients post-operatively. SKP wrote the paper with revision. All authors read and approved the final manuscript.

\section{Funding}

This study had no funding from any resource.

\section{Availability of data and materials}

The datasets used and/or analysed during the current study are available from the corresponding author on reasonable request.

\section{Ethics approval and consent to participate}

This study was approved by the Research Ethics Committee of the Seth G.S. Medical College and K.E.M., reference number of approval: IEC 2018/02/213. The patient included in this study gave written informed consent to participate in this research.

Consent for publication

The patient included in this study gave written informed consent to publish. 


\section{Competing interests}

The authors declare that they have no competing interests.

Received: 12 November 2019 Accepted: 5 February 2020

Published online: 10 June 2020

\section{References}

1. Assimos DG, Boyce WH, Harrison LH, McCullough DL, Kroovand RL, Sweat KR (1989) The role of open stone surgery since extracorporeal shock wave lithotripsy. J Urol 142:263-267

2. Honeck P, Wendt-Nordahl G, Krombach P, Bach T, Hacker A, Alken P et al (2009) Does open stone surgery still play a role in the treatment of urolithiasis? Data of a primary urolithiasis centre. J Endourol 23:1209-1212

3. Bichler KH, Lahme S, Strohmaier WL (1997) Indications for open stone removal of urinary calculi. Urol Int 59:102-108

4. Paik ML, Resnick MI (2000) Is there a role for open stone surgery? Urol Clin N Am 27:323-331

5. Aboutaleb H, Omar M, Salem S, Elshazly M (2016) Management of upper ureteral stones exceeding $15 \mathrm{~mm}$ in diameter: Shock wave lithotripsy versus semirigid ureteroscopy with holmium: yttrium-aluminum-garnet laser lithotripsy. SAGE Open Med 4:2050312116685180

6. El-Feel A, Abouel-Fettouh H, Abdel-Hakim AM (2007) Laparoscopic transperitoneal ureterolithotomy. J Endourol 21:50-54
7. Watson GM, Landers B, Nauth-Misir R, Wickham JE (1993) Developments in the ureteroscopes, techniques and accessories associated with laser lithotripsy. World J Urol 11:19-25

8. Tiselius HG (2005) Removal of ureteral stones with extracorporeal shock wave lithotripsy and ureteroscopic procedures. What can we learn from the literature in terms of results and treatment efforts? Urol Res 33:185-190

9. Fan S, Gong B, Hao Z, Zhang L, Zhou J, Zhang Y, Liang C (2015) Risk factors of infectious complications following flexible ureteroscope with a holmium laser: a retrospective study. Int J Clin Exp Med 8(7):11252-11259

10. Bansal A, Purkait B, Kumar M, Sankhwar S, Aeron R, Goel S (2016) Chain of stones in distal ureter: is there any role of open ureterolithotomy in era of endourological intervention? SM J Urol 2(1):1016

11. Gaur DD, Trivedi S, Prabhudesai MR, Madhusudhan HR, Gopichand M (2002) Laparoscopic ureterolithotomy: technical considerations and long term follow-up. BJU Int 89:339-343

12. Wolf JS (2007) Treatment selection and outcomes: ureteral calculi. Urol Clin N Am 34:421-430

13. Ganpule AP, Prashant J, Desai MR (2012) Laparoscopic and robot-assisted surgery in the management of urinary lithiasis. Arab J Urol 10(1):32-39

\section{Publisher's Note}

Springer Nature remains neutral with regard to jurisdictional claims in published maps and institutional affiliations.

\section{Submit your manuscript to a SpringerOpen ${ }^{\odot}$ journal and benefit from:}

- Convenient online submission

- Rigorous peer review

- Open access: articles freely available online

- High visibility within the field

- Retaining the copyright to your article

Submit your next manuscript at $\boldsymbol{\nabla}$ springeropen.com 